\title{
Copper(II)-induced self-oligomerization of $\alpha$-synuclein
}

\author{
Seung R. PAIK ${ }^{\star 1}$, Hyun-Ju SHIN*, Ju-Hyun LEE*, Chung-Soon CHANG* and Jongsun KIM† \\ *Department of Biochemistry, College of Medicine, Inha University, 253 Yonghyun-Dong, Nam-Ku, Inchon 402-751, Korea, and †Department of Microbiology, \\ College of Medicine, Yonsei University, Shinchon-Dong 134, Seodaemoon-Ku, Seoul 120-752, Korea
}

$\alpha$-Synuclein is a component of the abnormal protein depositions in senile plaques and Lewy bodies of Alzheimer's disease (AD) and Parkinson's disease respectively. The protein was suggested to provide a possible nucleation centre for plaque formation in $\mathrm{AD}$ via selective interaction with amyloid $\beta / \mathrm{A} 4$ protein $(\mathrm{A} \beta)$. We have shown previously that $\alpha$-synuclein has experienced selfoligomerization when $\mathrm{A} / 325-35$ was present in an orientationspecific manner in the sequence. Here we examine this biochemically specific self-oligomerization with the use of various metals. Strikingly, copper(II) was the most effective metal ion affecting $\alpha$-synuclein to form self-oligomers in the presence of coupling reagents such as dicyclohexylcarbodi-imide or $N$-(ethoxycarbonyl)-2-ethoxy-1,2-dihydroquinoline. The size distribution of the oligomers indicated that monomeric $\alpha$-synuclein was oligomerized sequentially. The copper-induced oligomerization was shown to be suppressed as the acidic C-terminus of $\alpha$ - synuclein was truncated by treatment with endoproteinase Asp$\mathrm{N}$. In contrast, the A $\beta 25-35$-induced oligomerizations of the intact and truncated forms of $\alpha$-synuclein were not affected. This clearly indicated that the copper-induced oligomerization was dependent on the acidic $\mathrm{C}$-terminal region and that its underlying biochemical mechanism was distinct from that of the A $\beta 25-35$ induced oligomerization. Although the physiological or pathological relevance of the oligomerization remains currently elusive, the common outcome of $\alpha$-synuclein on treatment with copper or A $\beta 25-35$ might be useful in understanding neurodegenerative disorders in molecular terms. In addition, abnormal copper homoeostasis could be considered as one of the risk factors for the development of disorders such as AD or Parkinson's disease.

Key words: Alzheimer's disease, Lewy body, Parkinson's disease, protein-aggregation, neurodegenerative disease.

\section{INTRODUCTION}

In the neurodegenerative diseases, $\alpha$-synuclein has been implicated in the formation of abnormal protein depositions in the brain by participating in senile plaques and Lewy bodies of Alzheimer's disease (AD) and Parkinson's disease (PD) respectively [1-5]. Senile plaque, a neuropathological hallmark of $\mathrm{AD}$, is an extracellular proteinaceous amyloid deposit in which a 39-43-residue amyloid $\beta / \mathrm{A} 4$ protein $(\mathrm{A} \beta)$ derived from its much larger precursor protein (APP) has been enriched as the major constituent [6]. It also contains another 35-residue peptide fragment called non-A $\beta$ component of AD amyloid (NAC) as a secondary component, amounting to less than $10 \%$ of the $\mathrm{A} \beta$ [1]. This NAC is derived from its precursor (NACP), also known as $\alpha$-synuclein [7]. It was reported that APPs, which could be processed to generate the pathological $\mathrm{A} \beta$, were ubiquitously expressed throughout the body; in addition, the resulting $\mathrm{A} \beta$ was secreted in a soluble form from various cell cultures under physiological conditions [8-11]. The NAC and/or the $\alpha$-synuclein have therefore been hypothesized to have significant roles during the formation of the senile plaque by possibly providing a nucleation centre. In fact, it was demonstrated that $\alpha$-synuclein caused an aggregation of A $\beta 1-38$ presumably seeded by an SDSresistant 1:1 complex between the two molecules in vitro when incubated at a molar ratio of $1: 125$ ( $\alpha$-synuclein to A $\beta 1-38)$ [12]. This nucleating complex was formed through a specific hydrophobic interaction between the last 15 residues of the NAC region of $\alpha$-synuclein and the $\mathrm{A} \beta 25-35$ sequence [12]. In addition, it has been shown that the $\alpha$-synuclein gene has undergone missense mutations in familial PD, which resulted in replacements of the alanine residue at position 30 or 53 with proline or threonine respectively $[13,14]$. The protein was immunohistochemically localized in Lewy bodies in an intact form even in the patients with sporadic PD as well as those with dementia with Lewy bodies $[3,15,16]$. It was therefore suggested that $\alpha$-synuclein might have an important pathological function in its native form for the development of sporadic PD, which might be enhanced by the mutation for the familial cases.

The primary structure of $\alpha$-synuclein can be divided into three functional regions: an N-terminal segment (residues 1-60) in which five of seven KTKEGV repeats are localized is followed by a hydrophobic region of the NAC (residues 61-95), which shows a strong tendency to form a $\beta$-pleated sheet on the basis of predictions of secondary structure [17]; at the C-terminus is an acidic region especially enriched with acidic amino acid residues and proline residues. This acidic region is most variable in several isoforms of the protein isolated from various sources such as Torpedo, canary, cow and human [1,7,18-20]. Conformational analysis of the heat-stable recombinant human $\alpha$-synuclein indicated that the protein existed in an elongated "natively unfolded' structure that could cause the protein to be readily involved in various protein-protein interactions [21,22]. Recently we have demonstrated that $\alpha$-synuclein experienced self-oligomerization in the presence of A $\beta 25-35$ through a sequence- and orientation-specific interaction [23]. Because this marked transition of $\alpha$-synuclein from its disordered state to a certain structure that led to self-oligomerization could be valuable in understanding biochemical mechanisms for the $\alpha$-synucleinrelated neurodegenerative disorders, we decided to pursue this phenomenon further with various metal ions.

Not only do metals reflect physiological factors that can influence the protein structure, but transition metals especially are essential for the survival of organisms by participating in various biologically important redox reactions. However, these

Abbreviations used: $\mathrm{A} \beta$, amyloid $\beta / \mathrm{A} 4$ protein; $\mathrm{AD}$, Alzheimer's disease; APP, A $\beta$ precursor protein; Asp-N, endoproteinase Asp-N; $\mathrm{BCA}$, bicinchoninic acid; DCCD, dicyclohexylcarbodi-imide; EEDQ, $N$-(ethoxycarbonyl)-2-ethoxy-1,2-dihydroquinoline; NAC, non-A $\beta$ component of AD amyloid; PD, Parkinson's disease; TFA, trifluoroacetic acid.

1 To whom correspondence should be addressed (e-mail srpaik@dragon.inha.ac.kr). 
metals can be also harmful because of the same redox reactions or direct molecular interactions with biomacromolecules [24]. In fact, much evidence for the possible involvement of metals in the pathogenesis of AD and PD has been accumulated [25-36]. To uncover the molecular relationship between metals and the neurodegenerative disorders, we have examined the phenomenon of self-oligomerization of $\alpha$-synuclein in the presence of various metal ions by using coupling reagents such as dicyclohexylcarbodi-imide (DCCD) or $N$-(ethoxycarbonyl)-2-ethoxy-1,2-dihydroquinoline (EEDQ). We have reached the surprising finding that copper(II) was actually the most effective metal ion, clearly affecting $\alpha$-synuclein in forming self-oligomers. Our results also indicated that the metal interaction and the subsequent structural alterations of the 'natively unfolded' protein were attributed to the $\mathrm{C}$-terminal acidic region of $\alpha$-synuclein.

\section{EXPERIMENTAL}

\section{Materials}

The recombinant $\alpha$-synuclein gene kindly provided by Dr. R. Jakes in pRK172 was transformed in Escherichia coli BL21(DE3)PlysS and the protein was prepared by the procedure previously described [32]. The completely purified protein was kept in $20 \mathrm{mM}$ Mes, $\mathrm{pH} 6.5$, at a concentration of $1.1 \mathrm{mg} / \mathrm{ml}$ and stored at $-70{ }^{\circ} \mathrm{C}$. The protein was quantified with a bicinchoninic acid (BCA) assay from Pierce in accordance with the manufacturer's procedure by using BSA as a standard protein [32]. The amount of $\alpha$-synuclein determined with this procedure was well correlated with that of the previously described method of quantification obtained with a molar absorption coefficient at $274 \mathrm{~nm}$ of $5600 \mathrm{M}^{-1} \cdot \mathrm{cm}^{-1}$ [21]. The coupling reagents DCCD and EEDQ were obtained from Sigma. Endoproteinase Asp-N from Pseudomonas fragi (Asp-N; EC 3.4.24.33), A $\beta 25-35$, SDS, dithiothreitol, silver nitrate, sodium carbonate, sodium citrate, Coomassie Blue G, Phenol Red and Sephadex G-25 (coarse) were also from Sigma. Acetonitrile, ethanol and methanol were from Fisher Scientific. Glycerol, formaldehyde, $\mathrm{CuCl}_{2}, 2 \mathrm{H}_{2} \mathrm{O}$ and $\mathrm{ZnCl}_{2}$ were obtained from Junsei Chemical Co. (Tokyo, Japan). $\mathrm{MgCl}_{2}, 6 \mathrm{H}_{2} \mathrm{O}$ and $\mathrm{CaCl}_{2}, 4 \mathrm{H}_{2} \mathrm{O}$ were from Yakuri Pure Chemicals Co. (Osaka, Japan). $\mathrm{AlCl}_{3}, \mathrm{FeCl}_{2}, 4 \mathrm{H}_{2} \mathrm{O}$ and $\mathrm{CoCl}_{2}, 6 \mathrm{H}_{2} \mathrm{O}$ were purchased from Sigma; $\mathrm{NiCl}_{2}$ was from Aldrich. Acetic acid was from Duksan Chemical Co. (Seoul, Korea). Glutaraldehyde [50\% (v/v) in water] and DMSO were obtained from Fluka and Merck respectively. The precast gels for Tricine/SDS/PAGE [10-20\% (w/v) gel] were provided from Novex (San Diego, CA).

\section{Effects of metal on the self-oligomerization of $\alpha$-synuclein}

The self-oligomerization of $\alpha$-synuclein in the presence of metal ions such as $\mathrm{Mg}^{2+}, \mathrm{Al}^{3+}, \mathrm{Ca}^{2+}, \mathrm{Fe}^{2+}, \mathrm{Co}^{2+}, \mathrm{Ni}^{2+}, \mathrm{Cu}^{2+}$ and $\mathrm{Zn}^{2+}$ were examined with respect to the formation of discrete ladders on the Tricine/SDS/PAGE gel. $\alpha$-Synuclein $(100 \mathrm{pmol})$ was preincubated with each metal ion $(0.5 \mathrm{mM})$ in $20 \mathrm{mM}$ Mes, $\mathrm{pH}$ 6.5 , for $45 \mathrm{~min}$ at $37^{\circ} \mathrm{C}$. The metal ions were initially prepared in stocks of $5 \mathrm{mM}$ with the Mes buffer. The reactions proceeded for a further $1 \mathrm{~h}$ at $37^{\circ} \mathrm{C}$ with the coupling reagent, either $1 \mathrm{mM}$ DCCD or $0.3 \mathrm{mM} E E D Q$, which were kept in stock solution in ethanol and DMSO respectively. The organic solvents were always less than $10 \%$ in the final reaction mixtures. Chemical cross-linking was terminated by mixing the sample with a Tricine/SDS/PAGE sample buffer consisting of $8 \%$ (w/v) SDS, $24 \%$ (v/v) glycerol, $0.015 \%$ Coomassie Blue G and $0.005 \%$ Phenol Red in $0.9 \mathrm{M}$ Tris $/ \mathrm{HCl}, \mathrm{pH} \mathrm{8.45}$, at a $1: 1$ (v/v) ratio, followed by boiling for $5 \mathrm{~min}$. The samples were analysed by Tricine/SDS/PAGE [10-20\% (w/v) precast gel] in accordance with the procedure provided by the manufacturer (Novex); the ladder formations were revealed with the silver staining procedure of Morrisey [37]. For the experiments on the $\mathrm{pH}$ dependence of the copper- and zinc-induced oligomerizations, the protein was cross-linked with $0.3 \mathrm{mM}$ EEDQ in $20 \mathrm{mM}$ sodium phosphate buffer at $\mathrm{pH} 6.5$ or 7.5 in the presence of each metal at either 0.5 or $2 \mathrm{mM}$.

\section{Treatment of $\alpha$-synuclein with Asp-N}

$\alpha$-Synuclein $(2.2 \mu \mathrm{g})$ was subjected to a limited proteolysis with $2 \mathrm{ng}$ of Asp-N in $20 \mathrm{mM}$ Mes, pH 6.5 (final volume $20 \mu \mathrm{l}$ ), at $37^{\circ} \mathrm{C}$ for various durations. After heat-inactivation at $90^{\circ} \mathrm{C}$ for $10 \mathrm{~min}$, the samples were analysed with the precast Tricine gradient polyacrylamide gel from Novex. To prepare the proteolytic products Dn1 and Dn2, $\alpha$-synuclein $(5 \mathrm{mg})$ was digested with the Asp-N at a ratio of $2000: 1$ (w/w) for $4 \mathrm{~h}$ at $37^{\circ} \mathrm{C}$ in $20 \mathrm{mM}$ Mes, pH 6.5 (final volume $5 \mathrm{ml}$ ). After termination of the restricted proteolysis by heat treatment, the sample was dialysed overnight against 4 litres of $50 \mathrm{mM}$ Tris/ $\mathrm{HCl}, \mathrm{pH} 8.0$, with an additional buffer change. The resulting modified proteins were separated by MonoQ anion-exchange chromatography with FPLC (Pharmacia). The chromatography was done with a linear gradient of $0-2 \mathrm{M} \mathrm{NaCl}$ in $50 \mathrm{mM}$ Tris/HCl, $\mathrm{pH} 8.0$, at a flow rate of $1 \mathrm{ml} / \mathrm{min}$. Whereas Dn2 was obtained in the flow-through fraction, Dn1 was eluted at $0.1-0.2 \mathrm{M} \mathrm{NaCl}$. The Dn1 was dialysed against $20 \mathrm{mM}$ Mes, $\mathrm{pH} 6.5$, and concentrated on a Centricon-3 (Amicon). The Dn2 was further purified with HPLC (Gilson) by using a $\mathrm{C}_{4}$ reverse-phase column (Millipore). The reverse-phase HPLC was performed with a gradient of $0-80 \%$ $(\mathrm{v} / \mathrm{v})$ acetonitrile in $0.1 \%(\mathrm{v} / \mathrm{v})$ trifluoroacetic acid (TFA) at a flow rate of $1 \mathrm{ml} / \mathrm{min}$. The Dn2 collected at $30-35 \%(\mathrm{v} / \mathrm{v})$ acetonitrile was freeze-dried and resuspended in the Mes buffer. The proteins were quantified either by amino acid composition analysis or with a protein assay kit using BCA from Pierce. These modified proteins were directly subjected to amino acid sequence analysis with the automatic Edman degradation procedure with the use of an ABI476A peptide sequencer. MS either with a Micromass Quattro II in electrospray ionization-positive mode or with a JMS HX-110/110A for matrix-assisted laser desorption ionization MS (MALDI-MS) in the Korea Basic Science Center was also used to identify the proteins.

\section{Dissociation constant between copper(II) and $\alpha$-synuclein}

The reaction mixtures containing $2.5 \mu \mathrm{M} \alpha$-synuclein and various concentrations of $\mathrm{CuCl}_{2}$ in $20 \mathrm{mM} \mathrm{Mes}, \mathrm{pH}$ 6.5, were incubated at $37^{\circ} \mathrm{C}$ for $40 \mathrm{~min}$. The bound copper on $\alpha$-synuclein was separated from unbound copper by a centrifuge column procedure (Penefsky column) with Sephadex G-25 (coarse) [38]. Preswollen gel packed in a disposable $1 \mathrm{ml}$ syringe was compressed by centrifugation at $500 \mathrm{~g}$ (1600 rev./min; HA1000-3; Hanil Industrial Co., Inchon, Korea) for $1 \mathrm{~min}$. A sample of the mixture $(100 \mu \mathrm{l})$ was transferred to the top of the dehydrated gel and centrifuged for a further $1.5 \mathrm{~min}$ at the same speed. The eluate was collected and its protein and copper contents were determined. The recovery of proteins was $52.5 \%$ on average. The amount of copper was quantified by the protein assay procedure (Pierce) with BCA [39], with slight modifications. The sample $(20 \mu \mathrm{l})$ containing the bound copper was combined with microreagent $\mathrm{A}(100 \mu \mathrm{l})$, containing $8 \%(\mathrm{w} / \mathrm{v})$ sodium carbonate, $1.6 \%(\mathrm{w} / \mathrm{v}) \mathrm{NaOH}$ and $1.6 \%(\mathrm{w} / \mathrm{v})$ sodium tartrate in which the $\mathrm{pH}$ had been adjusted to 11.25 with sodium bicarbonate, and micro-reagent B $(96 \mu \mathrm{l})$, which consisted of $4 \%(\mathrm{w} / \mathrm{v})$ BCA. After ascorbic acid had been added to a final concentration of $5 \mathrm{mM}$ in a total volume of $400 \mu \mathrm{l}$, the mixture was incubated at 
$37^{\circ} \mathrm{C}$ for $1 \mathrm{~h}$ and its absorbance at $562 \mathrm{~nm}$ was measured. The molarity of copper was calculated from a standard curve obtained with various concentrations of $\mathrm{CuCl}_{2}$ subjected to the above reaction. To obtain a dissociation constant and the number of copper ions bound to the protein, a double-reciprocal plot was performed between total and bound copper concentrations.

\section{RESULTS}

\section{Self-oligomerization of $\alpha$-synuclein in the presence of various metal ions}

Interactions of metals with $\alpha$-synuclein and their possible involvement in structural transitions of the protein leading to selfoligomerization were examined with Tricine/SDS/PAGE $[10-20 \%(\mathrm{w} / \mathrm{v})$ gel] by using the zero-length cross-linkers DCCD or EEDQ. Cations such as $\mathrm{Mg}^{2+}, \mathrm{Al}^{3+}, \mathrm{Ca}^{2+}, \mathrm{Fe}^{2+}, \mathrm{Co}^{2+}, \mathrm{Ni}^{2+}$, $\mathrm{Cu}^{2+}$ and $\mathrm{Zn}^{2+}$ freshly prepared at a final concentration of $0.5 \mathrm{mM}$ in $20 \mathrm{mM}$ Mes, $\mathrm{pH}$ 6.5, were preincubated with $100 \mathrm{pmol}$ of $\alpha$-synuclein, followed by cross-linking for $1 \mathrm{~h}$ in the presence of $1 \mathrm{mM}$ DCCD. An analysis of the cross-linked products on the Tricine/SDS/PAGE gel revealed that copper(II) induced the self-oligomerization of $\alpha$-synuclein, which appeared as a discrete ladder; other ions elicited little oligomerization (Figure 1A). The relative size distribution of the oligomers was estimated as 17,38 , $49,66,87,102$ and $118 \mathrm{kDa}$. To find the stoichiometry of $\alpha$ synuclein in the oligomers, the molecular masses were divided by $17 \mathrm{kDa}$, yielding the resulting values 1.0, 2.2, 2.9, 3.9, 5.1, 6.0 and 6.9 , indicating that the oligomers were produced by the sequential addition of monomeric $\alpha$-synuclein. Especially with iron, the metals caused heterogeneous non-specific protein aggregation that appeared as a smear on the gel, which was clearly distinct from the specific copper-induced oligomerization. To ensure that this oligomerization was solely attributable to the metal ion, another hydrophobic coupling reagent EEDQ was used instead at a final concentration of $0.3 \mathrm{mM}$ in $20 \mathrm{mM}$ Mes, $\mathrm{pH}$ 6.5, to detect the metal-induced oligomers. It had already been reported that EEDQ was more effective than DCCD in revealing A $\beta 25-35$ induced oligomerization [40]. Even with EEDQ, copper was the most effective metal ion in generating the oligomers (Figure 1B). However, this oligomerization was completely suppressed in the presence of $0.1 \mathrm{mM}$ EDTA, indicating a potential role of the metal in the formation of oligomers (results not shown). The oligomeric bands that were barely detectable with zinc, cobalt and nickel in the presence of DCCD became apparent with EEDQ. Aluminium also caused smearing of the protein, possibly due to non-specific protein aggregation in the presence of the coupling reagent. In fact these metal-induced oligomerizations were suspected to be induced by selective hydrophobic interactions because a water-soluble coupling reagent, 1-ethyl-3-(3dimethylaminopropyl)carbodi-imide (EDAC), failed to crosslink $\alpha$-synuclein into a discrete ladder on the gel (results not shown).

The copper- and zinc-induced self-oligomerizations were investigated more closely at various metal concentrations during the cross-linking reactions at two $\mathrm{pH}$ values, 6.5 and 7.5. When the metal-induced oligomerizations were performed in $20 \mathrm{mM}$ Tris/ $\mathrm{HCl}, \mathrm{pH} 7.5$, the copper-induced oligomerization was suppressed to the basal level (results not shown). To confirm whether this was due to $\mathrm{pH}$ or to the buffering component, the oligomerizations with EEDQ were performed in $20 \mathrm{mM}$ sodium phosphate buffer at pH 6.5 (Figure 2A) and pH 7.5 (Figure 2B). The result showed clearly that the oligomers produced by the metals at $\mathrm{pH} 6.5$ disappeared almost completely at $\mathrm{pH} 7.5$, indicating that the metal-induced oligomerization was $\mathrm{pH}$ dependent, unlike $\mathrm{A} \beta$-induced oligomerization, which was not

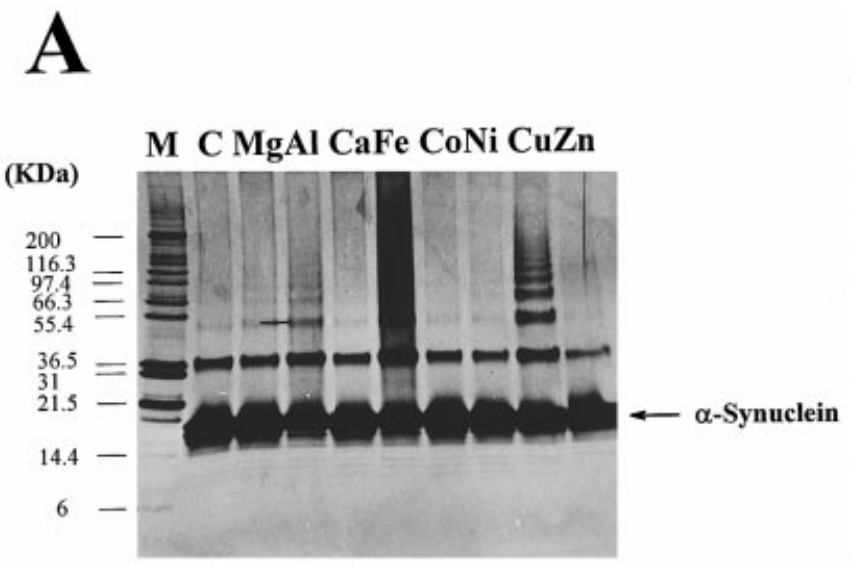

\section{B}

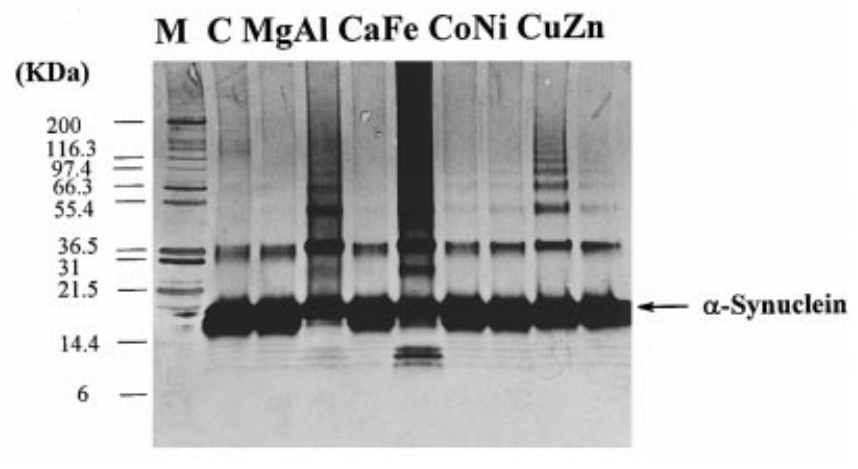

Figure 1 Effects of metal ions on the self-oligomerization of $\alpha$-synuclein in the presence of the cross-linkers DCCD (A) and EEDQ (B)

The oligomerizations were examined by using $100 \mathrm{pmol}$ of $\alpha$-synuclein and the metal ions (each at $0.5 \mathrm{mM}$ ) in $20 \mathrm{mM}$ Mes, pH 6.5, with either $1 \mathrm{mM}$ DCCD or $0.3 \mathrm{mM} \mathrm{EEDQ}$. The ladder formations were analysed with Tricine/SDS/PAGE [10-20\% (w/v) gel] (Novex) and revealed with silver staining. Lane $\mathrm{M}$, standard molecular markers; lane $\mathrm{C}$, controls containing $\alpha$ synuclein and cross-linkers in the absence of metal ions. The metal ions used are shown on the top of each lane. The standard marker proteins employed were as follows: myosin (rabbit muscle) (200 kDa), $\beta$-galactosidase (E. coli) (116.3 kDa), phosphorylase $b$ (rabbit muscle) $(97.4 \mathrm{kDa}), \mathrm{BSA}(66.3 \mathrm{kDa})$, glutamate dehydrogenase (bovine liver) $(55.4 \mathrm{kDa})$, lactate dehydrogenase (pig muscle) (36.5 kDa), carbonic anhydrase (bovine erythrocyte) (31 kDa), soybean trypsin inhibitor (21.5 kDa), lysozyme (hen's-egg white) (14.4 kDa) and aprotinin (bovine lung) $(6 \mathrm{kDa})$.

affected by $\mathrm{pH}$ in the presence of the same cross-linker [40]. In contrast with $\mathrm{A} \beta$-induced oligomerization, which increased gradually as the proportion of $\mathrm{A} \beta 25-35$ was raised to $1: 50(\alpha$ synuclein to $A \beta 25-35)$ and decreased thereafter, copper-induced oligomerization increased linearly to the final copper concentration of $3 \mathrm{mM}$.

\section{Copper-induced oligomerization was mediated by the C-terminal acidic region of $\alpha$-synuclein}

Because the acidic $\mathrm{C}$-terminal region has been considered to be responsible for the specific metal interactions, C-terminally truncated $\alpha$-synucleins were prepared with the aim of proving the functional significance of the region in treatment with metal. To obtain the truncated proteins, Asp-N, which hydrolyses peptide bonds on the $\mathrm{N}$-terminal side of either an aspartic or a cysteine residue, was used to process $\alpha$-synuclein, in which five of the six aspartic residues are found exclusively at the $\mathrm{C}$-terminus; there is 
A

B

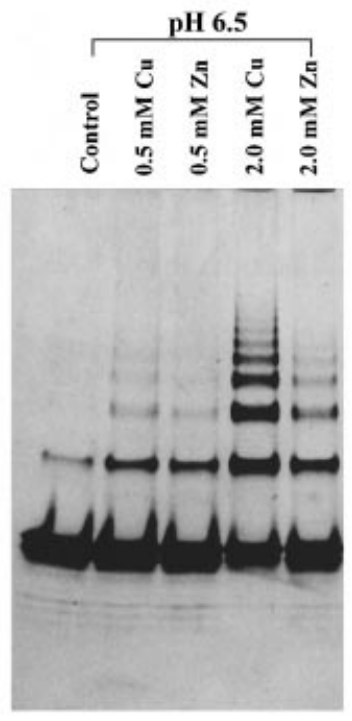

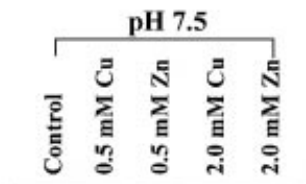

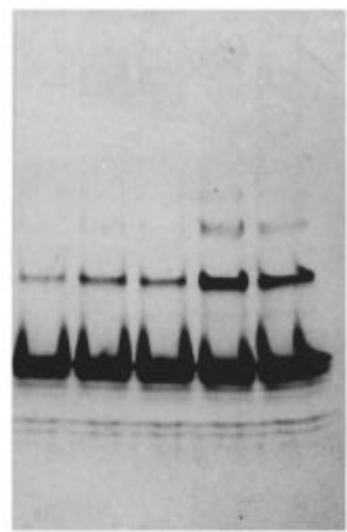

Figure $2 \mathrm{pH}$ dependence of the copper-induced and zinc-induced oligomerizations of $\alpha$-synuclein in the presence of EEDQ

Oligomerization reactions with the metal ions at either 0.5 or $2 \mathrm{mM}$ were performed in $20 \mathrm{mM}$ sodium phosphate buffer at pH $6.5(\mathbf{A})$ and pH $7.5(\mathbf{B})$. The controls contained $100 \mathrm{pmol}$ of $\alpha$ synuclein with $0.3 \mathrm{mM}$ EEDQ in $20 \mathrm{mM}$ sodium phosphate buffer at the appropriate $\mathrm{pH}$.

no cysteine residue in its primary structure. To accomplish limited digestion, $\alpha$-synuclein was treated with sufficiently dilute Asp-N (1100:1, w/w) at $37^{\circ} \mathrm{C}$ for various durations (Figure $\left.3 \mathrm{~A}\right)$.

\section{Table 1 Identification of Dn1, Dn2 and Dn3}

Dn1 and Dn2 were prepared by limited proteolysis of $\alpha$-synuclein with endoproteinase Asp-N. Dn3 was also obtained by proteolysis of Dn1 with Asp-N. All three products were subjected to partial amino acid sequence analysis by automated Edman degradation. Molecular masses were determined either by SDS/PAGE (Dn1 and Dn2) or by tandem MS (Dn3).

\begin{tabular}{llll}
\hline Product & N-terminal sequence & Molecular mass (Da) & $\begin{array}{l}\text { Sequence position in } \\
\alpha \text {-synuclein }\end{array}$ \\
\hline Dn1 & MDVFM & 11000 & $1-114$ \\
Dn2 & MDVFM & 9000 & $1-97$ \\
Dn3 & DQLGK & 1819.12 & $98-114$ \\
\hline
\end{tabular}

The limited proteolysis of $\alpha$-synuclein with the endoproteinase produced two modified proteins, designated Dn1 and Dn2, with approximate molecular masses of 11 and $9 \mathrm{kDa}$ respectively. When the metal effects on the oligomerizations of Dn1 and Dn2 were investigated directly with these reaction mixtures after inactivation of the proteinase by heat, copper-induced oligomerization was abolished as soon as Dn1 was generated (results not shown). However, this result was not conclusive because the mixture contained various protein/peptide fragments that could have interfered with the oligomerization of Dn1. Dn1 and Dn2 were therefore separated and analysed for their potentials for forming self-oligomers in the presence of copper. The truncated proteins were prepared in large quantities by incubating $\alpha$ synuclein with Asp-N at a dilution of $2000: 1$ (w/w) for $4 \mathrm{~h}$ at $37^{\circ} \mathrm{C}$ in $20 \mathrm{mM}$ Mes, pH 6.5, and separated by Mono-Q anionexchange chromatography after dialysis against $20 \mathrm{mM}$ Tris/ $\mathrm{HCl}, \mathrm{pH}$ 8.0. Whereas Dn2 was obtained in the flow-through

\section{A}

\section{B}
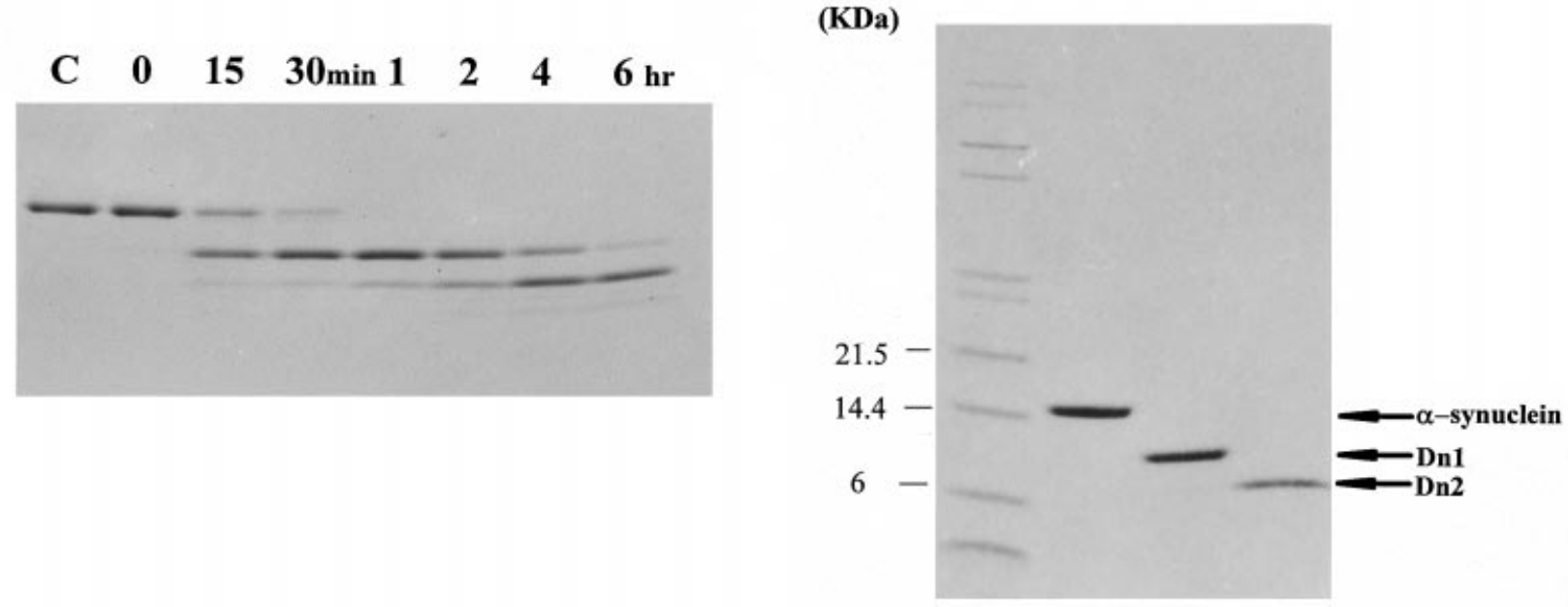

Figure 3 Limited proteolysis of $\alpha$-synuclein with Asp-N (A) and purification of its products (B)

$\alpha$-Synuclein $(2.2 \mu \mathrm{g})$ was digested with $2 \mathrm{ng}$ of Asp-N in $20 \mathrm{mM} \mathrm{Mes}, \mathrm{pH} 6.5$, at $37^{\circ} \mathrm{C}$ for various durations, as indicated $(\mathbf{A})$. After 10 min of heat inactivation of the protease at $90{ }^{\circ} \mathrm{C}$, the samples were subjected to Tricine/SDS/PAGE (Novex) and the gel was stained with Coomassie Brilliant Blue. After restricted proteolysis of $\alpha$-synuclein with Asp-N at a ratio of 2000:1 (w/w), purification of Dn1 and Dn2 was achieved with Mono $Q$ anion-exchange chromatography of FPLC and reverse-phase HPLC with a $C_{4}$ column. The purified products were subjected to Tricine/SDS/PAGE and stained with Coomassie Brilliant Blue (B). 
fraction, Dn1 was eluted at $0.15 \mathrm{M} \mathrm{NaCl}$ in $20 \mathrm{mM}$ Tris buffer. Because Dn2 in the flow-through contained minor contaminants as revealed by SDS/PAGE, the fraction was subjected to further purification by reverse-phase HPLC on a $\mathrm{C}_{4}$ column with a linear gradient of $0-80 \%$ acetonitrile in $0.1 \%(\mathrm{v} / \mathrm{v})$ TFA. After SDS/PAGE, the resulting modified $\alpha$-synucleins were revealed with Coomassie Brilliant Blue stain (Figure 3B).

To identify Dn1 and Dn2, the truncated proteins were subjected to partial amino acid sequencing from their N-termini. The two proteins shared a common N-terminus, Met-Asp-ValPhe-Met, which was the same as that of $\alpha$-synuclein (Table 1). Because direct measurements of the molecular mass of the truncated proteins by MS were unsuccessful, the differences at their C-termini were examined by further treating Dn1 with Asp$\mathrm{N}$ and isolating a peptide fragment derived from Dn1 with the use of reverse-phase HPLC (Figure 4). After the complete conversion of Dn 1 to Dn2 by treatment with proteinase at $37^{\circ} \mathrm{C}$ for $4 \mathrm{~h}$ at a ratio of 1:2000 (Asp-N to Dn1) (Figure 4A), a small peak designated Dn3 separated from a major protein that was eluted at $44.8 \mathrm{~min}$ (Figure 4B), which migrated indistinguishably with authentic Dn2 on SDS/PAGE (results not shown). Dn3, which was confirmed by amino acid sequence analysis to have a partial N-terminal sequence of Asp-Gln-Leu-Gly-Lys, was further analysed by tandem MS (JMS HX-110/110A); its molecular mass was 1819.12 Da (Figure 4C). This indicated that Dn3, the only product from Dn1 after treatment with Asp-N, consisted of residues $98-114$ of $\alpha$-synuclein, which had a calculated molecular mass of $1827.06 \mathrm{Da}$. Consistently with a previous report [41], the two major preferential cleavage sites of $\alpha$-synuclein by Asp-N, yielding Dn1 and Dn2, were the Asp-115 and Asp-98 respectively. As summarized in Table 1, therefore, Dn 1 was a $C$-terminally modified $\alpha$-synuclein containing residues 1-114, whereas Dn2 was another truncated protein with 97 residues with the same N-terminus as Dn1. Dn1 and Dn2 were therefore re-designated $\alpha$-syn 114 and $\alpha$-syn97 respectively.

These intact and truncated forms of $\alpha$-synuclein were then used to investigate the copper-induced and $A / 25-35$-induced oligomerizations. When the three proteins were analysed by Tricine/SDS/PAGE [10-20\% (w/v) gel] in the presence of $0.3 \mathrm{mM}$ EEDQ, all three proteins contained small amounts of dimeric forms. The $\alpha$-synuclein band was split into a doublet in the presence of the cross-linker, which had previously been suspected to be due to intramolecular cross-linking [23]. The $\alpha$ syn114 sample contained a few minor contaminants that appeared only with silver staining (Figure 5A). These proteins were subjected to oligomerizations by copper treatment. Whereas $\alpha$ synuclein self-oligomerized into a discrete ladder as shown in Figure 5(B), $\alpha$-syn114 was not as effective as its parent molecule in terms of generating the oligomers. Oligomers of $\alpha$-syn97, however, were completely absent even after treatment with $2 \mathrm{mM}$ copper. These results showed clearly that copper-induced oligomerizations diminished as the $\mathrm{C}$-terminal region of $\alpha$ synuclein was truncated. The interaction between copper and the C-terminal acidic region was also investigated by observing the formation of oligomers from the three proteins in the presence of various metal concentrations. The oligomerization of the intact molecule increased with copper concentration, whereas those of $\alpha$-syn 114 and $\alpha$-syn97 were not affected (results not shown). It was therefore appropriate to consider the $\mathrm{C}$-terminus of $\alpha$ synuclein to be responsible for the specific copper interaction that led to self-oligomerization. Interestingly, however, the A $\beta 25-35$-induced oligomerizations of $\alpha$-synuclein and the modified proteins were not dependent on the C-terminus of the protein (Figure 5C), indicating that the two modes of oligomerization rely on totally different biochemical mechanisms

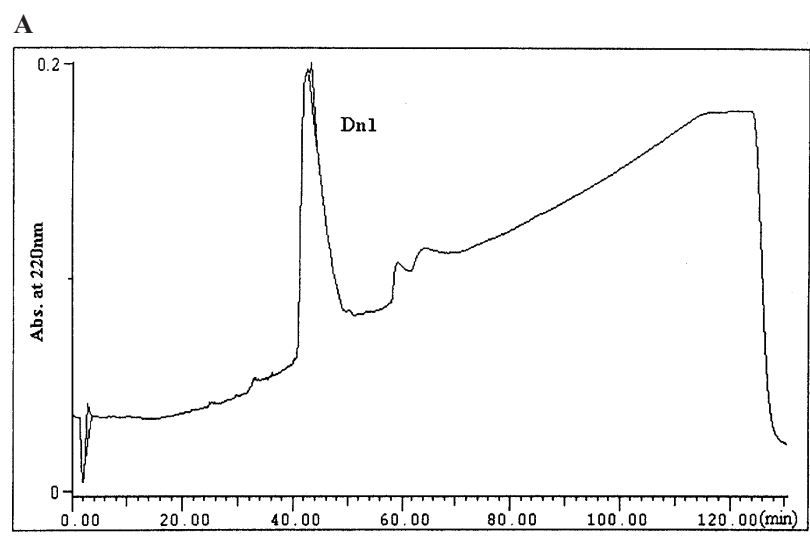

B

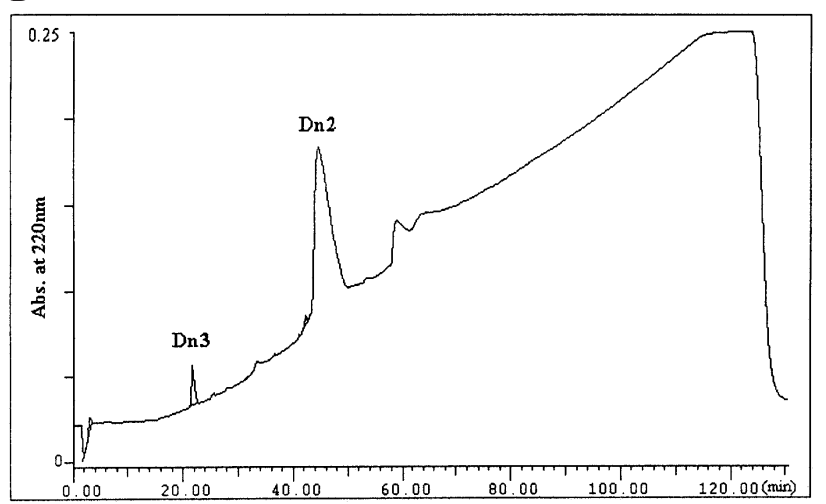

C

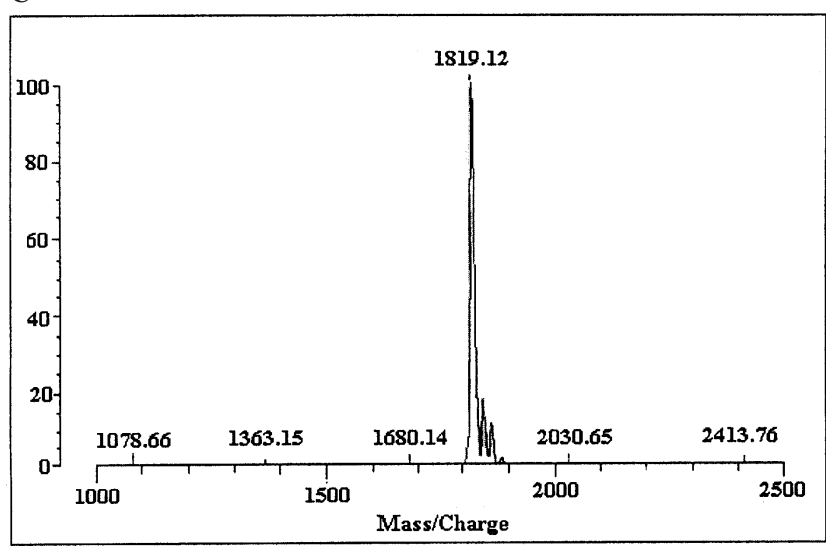

Figure 4 Identification of Dn1, Dn2 and Dn3 by reversed-phase HPLC (A, B) and tandem MS (C)

The elution of Dn1 from $\mathrm{C}_{4}$ reverse-phase HPLC with $0-80 \%(\mathrm{~V} / \mathrm{V})$ acetonitrile in $0.1 \%(\mathrm{~V} / \mathrm{V})$ TFA is shown (A). The proteolytic fragments derived from Dn1 after limited proteolysis with Asp$\mathrm{N}$ at a ratio of 2000:1 (Dn1 to Asp-N) were separated by reverse-phase HPLC (B). Dn2, confirmed by SDS/PAGE, was produced from Dn1 with another fragment, Dn3. The molecular mass of Dn3 was analysed by tandem MS (JMS HX-110/110A) (C).

leading to the common self-interactions. Thus the copper-induced self-oligomerization of $\alpha$-synuclein was highly dependent on the C-terminal acidic domain, whereas the NAC and/or the Nterminal region was responsible for the specific interaction with A $\beta 25-35$ leading to oligomerization. In fact, $\alpha$-synuclein has been suggested to contain at least two $\mathrm{A} \beta$-binding segments (residues 1-56 and 57-97) on the basis of a cross-linking experiment between the protein and ${ }^{125} \mathrm{I}-\mathrm{A} \beta$ [41]. 
A

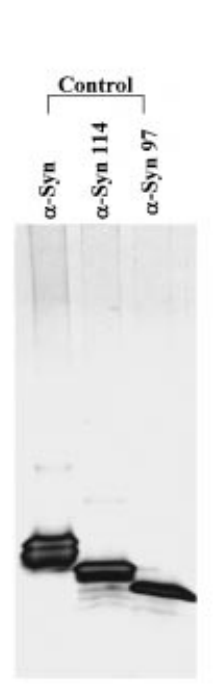

B

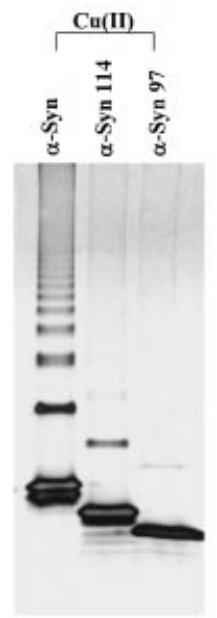

C

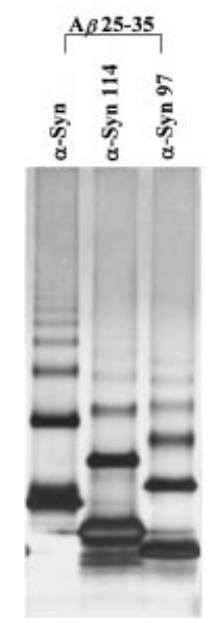

Figure 5 Self-oligomerization of $\alpha$-synuclein, $\alpha$-syn114 and $\alpha$-syn97 in the presence of copper ions or A $\beta 25-35$

Each protein was incubated with $0.3 \mathrm{mM} E E D Q$ in the absence of any effector $(\mathbf{A})$. Copper (final concentration $2 \mathrm{mM}$ ) was added in the presence of EEDQ to cause self-oligomerization (B). The A $\beta 25-35$-induced oligomerization of the protein was performed with $5 \mathrm{nmol}$ of $\mathrm{A} \beta 25-35$ and $\alpha$-synuclein $(0.1 \mathrm{nmol}), \alpha$-syn114 $(0.2 \mathrm{nmol})$ or $\alpha$-syn97 $(0.2 \mathrm{nmol})$ in the presence of the cross-linker (C). The samples were analysed by Tricine/SDS/PAGE [10-20\% (w/v) gel] and the oligomers were revealed with silver stain.

\section{Dissociation constant between $\alpha$-synuclein and copper(II)}

After the isolation and subsequent reduction of the proteinbound $\mathrm{Cu}^{2+}$, the actual metal binding to $\alpha$-synuclein was investigated with BCA, which selectively interacted with the cuprous cation $\left(\mathrm{Cu}^{+}\right)$. After the incubations of various concentrations of $\mathrm{CuCl}_{2}$ with the protein $(2.5 \mu \mathrm{M})$ in $20 \mathrm{mM}$ Mes, pH 6.5 , the protein-bound copper was separated from the free metal by a centrifuge column with Sephadex G-25. The bound copper was reduced with $5 \mathrm{mM}$ ascorbic acid and quantified with the BCA protein assay kit. The total and bound copper concentrations were analysed with a double-reciprocal plot to obtain the affinity and the number of copper ions bound to the protein (Figure 6). The dissociation constant was $59 \mu \mathrm{M}$ and the maximum concentration of bound copper was $13.6 \mu \mathrm{M}$. Because $52.5 \%$ of the protein was on average recovered from the centrifuge column, approx. 10.4 molecules of the copper were calculated to be bound to a single molecule of $\alpha$-synuclein. For comparison, the interaction of zinc with $\alpha$-synuclein was examined by measuring the amount of protein-bound metal by atomic absorption spectroscopy (AAS670; Shimadzu) after the centrifuge column procedure on preincubated reaction mixtures between the protein and various concentrations of zinc. The dissociation constant obtained ( $44 \mu \mathrm{M})$ between zinc and $\alpha$-synuclein was comparable to that for copper $(59 \mu \mathrm{M})$. In contrast, the maximum number of the zinc ions binding to each molecule of the protein was 3.0, which was one-third to one-quarter of the number of copper ions (results not shown). This might indicate that $\alpha$-synuclein contains additional specific binding sites for copper, which could be critical for effective self-oligomerization. However, it is not certain that all of the bound copper ions were necessary for oligomerization because some non-specific metal binding might have occurred as copper-induced oligomers or protein aggregates of $\alpha$-synuclein were produced. Alternatively, these non-specific interactions could be required for the formation of the oligomers.

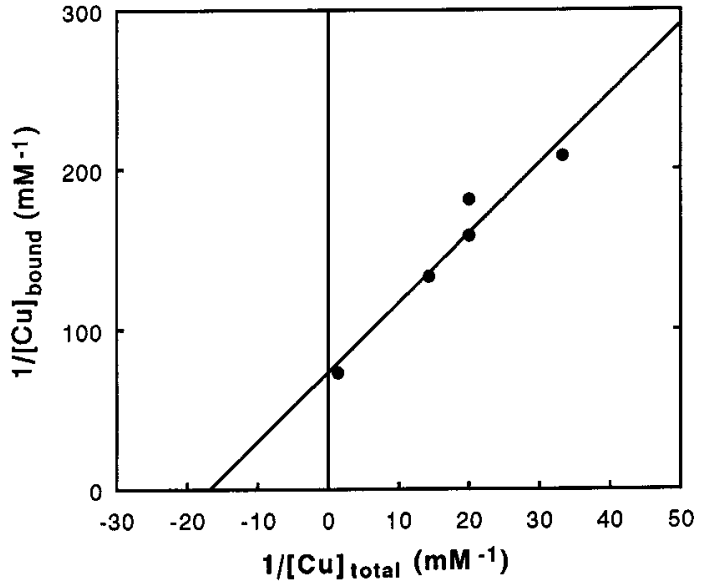

Figure 6 Binding between copper(II) and $\alpha$-synuclein

$\alpha$-Synuclein $(2.5 \mu \mathrm{M})$ was incubated with various concentrations of $\mathrm{CuCl}_{2}$ in $20 \mathrm{mM} \mathrm{Mes}$, pH 6.5 . The protein-bound copper was separated from free copper by using a centrifuge column with Sephadex G-25 (coarse). The amount of bound copper in the eluate was determined with slight modifications of the protein assay procedure with BCA after the complete reduction of the metal with $5 \mathrm{mM}$ ascorbic acid. A double-reciprocal plot of bound copper concentration against total copper concentration is shown.

\section{DISCUSSION}

Protein aggregations in the brain have been recognized to have a pathologically crucial role during the process of neurodegeneration, as in $\mathrm{A} \beta$ amyloid fibrils in senile plaques of $\mathrm{AD}$. A more detailed elucidation of basic mechanisms for the aggregation process would be beneficial in terms of providing therapeutic or preventive strategies for the protein aggregate-related neurodegenerative disorders [42]. In general, aggregate formation is considered to be dependent on protein concentration and durations of protein interactions in the presence of an appropriate initial nucleation centre [42]. Because $\mathrm{A} \beta$ was shown to be secreted in soluble form from various cell cultures under physiological conditions [8-11], it might require a nucleation centre for the protein to be selectively accumulated in the brains of AD patients. Therefore we hypothesized that brain-specific modifications of pre-existing protein after the onset of various pathological conditions could provide the possible nucleation centre on which protein aggregation might develop [23]. In this respect, $\alpha$-synuclein has been investigated for its participation in the seeding process of protein aggregation because the protein is found in both senile plaques and Lewy bodies of AD and PD respectively $[1,3]$. As previously described, $\alpha$-synuclein underwent self-oligomerization only in the presence of $A \beta 25-35$ out of all $\mathrm{A} \beta$ peptides tested, such as a reverse peptide $\mathrm{A} \beta 35-25$ as well as A $\beta 1-42, A \beta 1-40, A \beta 1-28$ and A $\beta 31-35[23,40]$. Intriguingly, the oligomers developed into SDS-resistant protein aggregates at high concentrations of $\mathrm{A} \beta 25-35$ and resulted in a lower level of soluble oligomers. This $\mathrm{A} \beta$-sequence-specific and orientationspecific self-oligomerization of $\alpha$-synuclein was therefore suggested to act as a nucleation centre for the aggregate formation [23]. Unfortunately, however, because the generation and presence of $\mathrm{A} \beta 25-35$ in the brain have not been described, we decided to pursue more physiological or pathological conditions under which the oligomerization of $\alpha$-synuclein might result.

When $\alpha$-synuclein was treated with various metals in the presence of a coupling reagent, we found that copper and zinc induced self-oligomerization. In general, metals can serve vital 
roles in natural proteins. They are involved in direct nucleophilic catalysis, electron transfer reactions and the stabilization of protein structures [43]. Their preferential interaction sites on proteins are those that provide either a negatively charged electrostatic surface or a hydrophobic shell in which specific interactions between the metal and a certain group of amino acids can be enhanced by the hydrophobic environment [43]. In $\alpha$-synuclein, our result shows clearly that the $\mathrm{C}$-terminal acidic region, which could provide the negatively charged surface, was responsible for the specific metal interaction leading to selfoligomerization. Therefore the pathological significance, if any, of the acidic region can be suggested because various forms of $\alpha$ synuclein would require different sets of pathological effectors for the protein to participate in various protein interactions.

Although oligomerizations induced by metal ions and by A $\beta 25-35$ might occur through mutually exclusive biochemical mechanisms, their resulting common phenomenon of self-oligomerization indicates that this type of structural transition of $\alpha$ synuclein might have thermodynamic advantages for the "natively unfolded' protein to be stabilized in the presence of specific pathological or physiological effectors. This transition from disorder to order, leading to oligomerization, seems to be mediated through the hydrophobic environment, which was accessed only with the relatively hydrophobic coupling reagents DCCD and EEDQ. In this respect, the specific interaction of copper with $\alpha$-synuclein, which might suppress the repulsive force generated between the $\mathrm{C}$-terminal acidic regions, could make the self-oligomerizing hydrophobic interactions more favourable. In spite of our current insufficient knowledge of the physiological or pathological significance of these self-oligomers, metal-induced self-oligomers might provide a possible nucleation centre for protein aggregations, eventually leading to Lewy bodies or senile plaques. In fact, abnormal metabolisms of copper or zinc and their involvement in the development of AD or PD have often been described [25-29,31,34-36]; for instance, the oral administration of zinc to AD patients yielded detrimental effects on cognition within a few days [25]. Although metalinduced toxicity has generally been ascribed to the generation of reactive oxygen species by the redox reaction of metals, the toxic effect of protein aggregate induced via direct interactions between metals and proteins has also been recognized frequently [30,32]. The metal-induced self-oligomers of $\alpha$-synuclein could therefore be considered a critical intermediate leading to protein aggregation, which could exhibit ultimate neurotoxicity possibly through the metal-mediated redox reactions [30].

Copper has been shown to be closely related to AD by interacting directly with APP or possibly causing $\mathrm{A} \beta$ aggregation [31]. The metal ions exist in chelated form in vivo primarily with caeruloplasmin as well as other biomolecules such as albumin, transcuprein, peptides and amino acids. Various concentrations of copper ions have been found throughout the body: 16-20 $\mu \mathrm{M}$ in blood, $15 \mu \mathrm{M}$ in the synaptic cleft and $0.5-2.5 \mu \mathrm{M}$ in cerebrospinal fluid [44]. Interestingly, the concentration in cerebrospinal fluid was increased 2.2-fold in AD patients [31]. It was reported that copper(II) was reduced to copper(I) by APP through an electron transfer reaction, leading to the formation of a disulphide bond in the protein. The resulting APP-Cu(I) complex could be toxic in the presence of $\mathrm{H}_{2} \mathrm{O}_{2}$ by producing reactive oxygen species including hydroxyl radicals and $\mathrm{O}_{2} \cdot{ }^{-}[31]$. In addition, the metal was suspected to participate in the actual A $\beta$ aggregation. Taken together, these observations could certainly make copper one of the risk factors for AD. Copper homoeostasis might therefore be another critical aspect to approaching the neurodegenerative disorders in molecular terms. In addition, the effect of zinc on oligomerization should not be underestimated from the pathological point of view, even though its efficiency was somewhat lower than that of copper, because not only has the metal been known to be actively involved in various biologically critical processes including synaptic transmission along with immunological and reproductive functions [45], but also because it has been implicated in neuronal cell death under certain conditions [46].

Recently, Spillantini et al. [47] extracted the polar filaments $(5-10 \mathrm{~nm})$ from Lewy bodies and showed them to be composed mainly of extended $\alpha$-synucleins existing parallel to the filament axis. It is speculated that the self-oligomers of $\alpha$-synuclein participate in the formation of Lewy bodies not only because the protein has been proposed to exist in an elongated 'natively unfolded' structure, but also because the oligomerizations observed in the presence of either $\mathrm{A} \beta 25-35$ or copper(II) were sequence-specific and orientation-specific phenomena that would result in protein aggregation with a certain polar structure. If $\alpha$ synuclein is a real endogenous and functionally critical factor in aggregation, investigations of biochemical details of the protein and the self-oligomerization processes might shed light on an approach to the neurodegenerative disorders in molecular terms. In addition, the fact that $\alpha$-synuclein is a copper-interactive protein would make it a new member of the cuproproteins including prion, monoamine oxidase, superoxide dismutase 1 and APP, closely related to various neurodegenerative diseases such as PD, AD, prion disease and familial amyotrophic lateral sclerosis [44]. This copper-induced oligomerization of $\alpha$-synuclein could therefore open up new scope for approaching the molecular aetiology of AD or PD in terms of not only $\alpha$-synuclein but also abnormal copper homoeostasis.

This study was supported by a grant (HMP-98-M-3-0042) from the Good Health Research and Development Project, the Ministry of Health and Welfare, Republic of Korea, and partly by a research fund from Inha University in 1998.

\section{REFERENCES}

1 Uĕda, K., Fukushima, H., Masliah, E., Xia, Y., Iwai, A., Yoshimoto, M., Otero, D. A. C. Kondo, J., Ihara, Y. and Saitoh, T. (1993) Proc. Natl. Acad. Sci. U.S.A. 90, 11282-11286

2 Iwai, A., Masliah, E., Yoshimoto, M., Ge, N., Flanagan, L., De Silva, H. A. R., Kittel, A. and Saitoh, T. (1995) Neuron 14, 467-475

3 Baba, M., Nakajo, S., Tu, P.-H., Tomita, T., Nakaya, K., Lee, V. M.-Y., Trojanowski, J. Q. and Iwatsubo, T. (1998) Am. J. Pathol. 152, 879-884

4 Clayton, D. F. and George, J. M. (1998) Trends Neurosci. 21, 249-254

5 Heintz, N. and Zoghbi, H. (1997) Nat. Genet. 16, 325-327

6 Selkoe, D. J. (1994) Annu. Rev. Neurosci. 17, 489-517

7 Jakes, R., Spillantini, M. G. and Goedert, M. (1994) FEBS Lett. 345, 27-32

8 Haass, C., Schlossmacher, M. G., Hung, A. Y., Vigo-Pelfrey, C., Mellon, A., Ostaszewski, B. L., Lieberburg, I., Ko0, E. H., Schenk, D., Teplow, D. B. and Selkoe, D. J. (1992) Nature (London) 359, 322-325

9 Seubert, P., Vigo-Pelfrey, C., Esch, F., Lee, M., Dovey, H., Davis, D., Sinha, S., Schlossmacher, M., Whaley, J., Swindlehurst, C. et al. (1992) Nature (London) 359, 325-327

10 Shoji, M., Golde, T. E., Ghiso, J., Cheung, T. T., Estus, S., Shaffer, L. M., Cai, X.-D., McKay, D. M., Tintner, R., Frangione, B. and Younkin, S. G. (1992) Science 258, 126-129

11 Busciglio, J., Gabuzda, D. H., Matsudaira, P. and Yankner, B. A. (1993) Proc. Natl. Acad. Sci. U.S.A. 90, 2092-2096

12 Yoshimoto, M., Iwai, A., Kang, D., Otero, D. A. C., Xia, Y. and Saitoh, T. (1995) Proc. Natl. Acad. Sci. U.S.A. 92, 9141-9145

13 Polymeropoulos, M. H., Lavedan, C., Leroy, E., Ide, S.E., Dehejia, A., Dutra, A., Pike, B., Root, H., Rubenstein, J., Boyer, R. et al. (1997) Science 276, 2045-2047

14 Krüger, R., Kuhn, W., Müller, T., Woitalla, D., Graeber, M., Kösel, S., Przuntek, H., Epplen, J. T., Schöls, L. and Riess, 0. (1998) Nat. Genet. 18, 106-108

15 Spillantini, M. G., Schmidt, M. L., Lee, V. M.-Y., Trojanowski, J. Q., Jakes, R. and Goedert, M. (1997) Nature (London) 388, 839-840

16 Takeda, A., Mallory, M., Sundsmo, M., Honer, W., Hansen, L. and Masliah, E. (1998) Am. J. Pathol. 152, 367-372 
17 Iwai, A., Yoshimoto, M., Masliah, E. and Saitoh, T. (1995) Biochemistry 34 10139-10145

18 Maroteaux, L. and Scheller, R. H. (1991) Mol. Brain Res. 11, 335-343

19 Uĕda, K., Saitoh, T. and Mori, H. (1994) Biochem. Biophys. Res. Commun. 205 1366-1372

20 George, J. M., Jin, H., Woods, W. S. and Clayton, D. F. (1995) Neuron 15, 361-372

21 Weinreb, P. H., Zhen, W., Poon, A. W., Conway, K. A. and Lansbury, Jr., P. T. (1996) Biochemistry 35, 13709-13715

22 Kim, J. (1997) Mol. Cells 7, 78-83

23 Paik, S. R., Lee, J.-H., Kim, D.-H., Chang, C.-S. and Kim, Y.-S. (1998) FEBS Lett. 421, 73-76

24 Candice, A. and Kaplan, J. (1998) Trends Biochem. Sci. 23, 135-138

25 Kaiser, J. (1994) Science 265, 1365

26 Bush, A. I., Pettingell, W. H., Multhaup, G., Paradis, M. D., Vonsattel, J.-P., Gusella, J. F., Beyreuther, K., Masters, C. L. and Tanzi, R. E. (1994) Science 265, 1464-1467

27 Fitzgerald, D. J. (1995) Science 268, 1920

28 Maggio, J. E., Esler, W. P., Stimson, E. R., Jennings, J. M., Ghilardi, J. R. and Mantyh, P. W. (1995) Science 268, 1920-1921

29 Bush, A. I., Moir, R. D., Rosenkranz, K. M. and Tanzi, R. E. (1995) Science 268 1921-1923

30 Smith, M. A., Harris, P. L. R., Sayre, L. M. and Perry, G. (1997) Proc. Natl. Acad. Sci. U.S.A. 94, 9866-9868

31 Multhaup, G., Schlicksupp, A., Hesse, L., Behler, D., Ruppert, T., Masters, C. L. and Beyreuther, K. (1996) Science 271, 1406-1409

32 Paik, S. R., Lee, J.-H., Kim, D.-H., Chang, C.-S. and Kim, J. (1997) Arch. Biochem. Biophys. 344, 325-334

Received 7 December 1998/1 March 1999; accepted 8 April 1999
33 Harrington, C. R. (1996) Mol. Med. Today 2, 4-6

34 Gorell, J. M., Johnson, C. C., Rybicki, B. A., Peterson, E. L., Kortsha, G. X., Brown, G. G. and Richardson, R. J. (1997) Neurology 48, 650-658

35 Kienzl, E., Puchinger, L., Jellinger, K., Linert, W., Stachelberger, H. and Jameson, R. F. (1995) J. Neurol. Sci. 134 (suppl.), 69-78

36 Logroscino, G., Marder, K., Graziano, J., Freyer, G., Slavkovich, V., Lolacono, N., Cote, L. and Mayeux, R. (1997) Neurology 49, 714-717

37 Morrissey, J. H. (1981) Anal. Biochem. 117, 307-310

38 Penefsky, H. S. (1977) J. Biol. Chem. 252, 2891-2899

39 Smith, P. K., Krohn, R. I., Hermanson, G. T., Mallia, A. K., Gartner, F. H., Provenzano, M. D., Fujimoto, E. K., Goeke, N. M., Olson, B. J. and Klenk, D. C. (1985) Anal. Biochem. 150, 76-85

40 Lee, J.-H., Shin, H.-J., Chang, C.-S. and Paik, S. R. (1998) Neurochem. Res. 23, 1427-1434

41 Jensen, P. H., Højrup, P., Hager, H., Nielsen, M. S., Jacobsen, L., Olesen, O. F., Gliemann, J. and Jakes, R. (1997) Biochem. J. 323, 539-546

42 Harper, J. D. and Lansbury, Jr., P. T. (1997) Annu. Rev. Biochem. 66, 385-407

43 Regan, L. (1995) Trends Biochem. Sci. 20, 280-285

44 Brown, D. R., Qin, K., Herms, J. W., Madlung, A., Manson, J., Strome, R., Fraser, P. E., Kruck, T., Bohlen, A., Schulz-Schaeffer, W. et al.(1997) Nature (London) 390 684-687

45 Huang, E. P. (1997) Proc. Natl. Acad. Sci. U.S.A. 94, 13386-13387

46 Choi, D. W. and Koh, J. Y. (1998) Annu. Rev. Neurosci. 21, 347-375

47 Spillantini, M. G., Crowther, R. A., Jakes, R., Hasegawa, M. and Goedert, M. (1998) Proc. Natl. Acad. Sci. U.S.A. 95, 6469-6473 